\title{
Determinants of Incomplete Vaccination Among Children Aged 12 to 23 Months in Gindhir District, Southeastern Ethiopia: Unmatched Case- Control Study
}

\author{
Demisu Zenbaba (iD) \\ Biniyam Sahiledengle (D) \\ Mitiku Bonsa Debela' \\ Tilahun Tufa' \\ Zinesh Teferu' \\ Abate Lette' \\ Habtamu Gezahegn (D) $^{2}$ \\ Damtew Solomon ${ }^{3}$ \\ Yohannes Tekalegn (1D) \\ 'Madda Walabu University Goba Referral \\ Hospital, School of Health Sciences, \\ Department of Public Health, Bale, \\ Ethiopia; ${ }^{2}$ Madda Walabu University \\ Goba Referral Hospital, School of \\ Medicine, Department of Physiology, \\ Bale, Ethiopia; ${ }^{3}$ Madda Walabu University \\ Goba Referral Hospital, School of \\ Medicine, Department of Anatomy, Bale, \\ Ethiopia
}

Correspondence: Demisu Zenbaba Email zdemisu@gmail.com
Background: Incomplete vaccination can put children at greater risk of acquiring vaccinepreventable diseases. In Ethiopia, vaccination coverage against vaccine-preventable diseases is still a significant and persistent public health challenge. Thus, the aim of this study was to identify the determinants of incomplete childhood vaccination among children aged 12-23 months in Gindhir District, Southeast Ethiopia.

Methods: A community-based unmatched case-control design was employed among children aged 12-23 months from 1 to 28 February 2020. A total of 254 cases and 508 controls were included using the stratified random sampling technique. Cases included children aged 12-23 months who missed at least one dose of the routine vaccination, and controls were the children with complete vaccination with all required doses. Binary logistic regression analyses were used to identify the independent factors for children's incomplete vaccination status.

Results: Of all assessed determinants, maternal knowledge about vaccination ( $\mathrm{AOR}=0.50$, 95\% CI: 0.31, 0.80), educational status (AOR=2.61, 95\% CI: $1.19,5.67)$, average monthly income $(\mathrm{AOR}=0.33,95 \% \mathrm{CI}: 0.15,0.77)$, model family $(\mathrm{AOR}=2.50,95 \% \mathrm{CI}: 1.51,4.14)$, taking TT vaccine $(\mathrm{AOR}=0.4595 \% \mathrm{CI}: 0.29,0.78)$, number of under five children (AOR= $4.9095 \%$ CI: $1.72,13.93)$ and birth order $(\mathrm{AOR}=6.33,95 \% \mathrm{CI}: 1.89,14.87)$ were found to have statistically significant association with childhood incomplete vaccination.

Conclusion: In this study, the mother's education, model family, birth order, average monthly income, and knowledge were some of the independent determinants of incomplete childhood vaccination. Improving maternal knowledge, income, and educational status should be the expectable measure to reduce incomplete vaccination.

Keywords: determinant, incomplete vaccination, children, Bale, Ethiopia

\section{Introduction}

Vaccinations have brought comprehensive health to many children globally and have been concrete in protecting children against vaccine-preventable diseases (VPDs) in low-and middle-income countries (LMICs). ${ }^{1-5}$ However, vaccination coverage is still a major public health challenge in many third world countries, particularly in resource-limited areas. ${ }^{6-8}$

Globally, about 22.6 million children under the age of one year were partially protected. Vaccination prevents the children from an estimated 2 to 3 million deaths 
every year by VPDs such as Diphtheria, Pertussis, Tetanus, and Measles. ${ }^{9}$ Nearly 107 million infants received the first dose of the DTP vaccine; however, around 22.4 million failed to receive three doses, leaving many children susceptible to VPDs worldwide. ${ }^{10,11}$ Globally, every eight out of ten children received the first dose of Polio vaccine, but only about four in ten received the third dose. ${ }^{12}$ The evidence from the Ethiopian Demographic Health Survey report 2016 indicated that about $39 \%$ of children aged 12 to 23 months received all basic vaccinations while $22 \%$ of children have not received. ${ }^{13}$

According to World Health Organization (WHO), incomplete vaccination refers to children who miss scheduled vaccinations for any reason due to health facility problems such as canceled vaccination schedules or vaccine stock-outs. ${ }^{14}$ The decision not to fully vaccinate a child is a decision to put the child at the risk of contracting a vaccine-preventable disease. ${ }^{15,16}$ In Ethiopia, the proportion of full vaccination coverage ranged from $36.6 \%$ in the remote region (Somali) to $100 \%$ in the central region (Addis Ababa). ${ }^{17}$ Given this range of coverage, only $18.6 \%$ of children, received the vaccinations on schedule and with the appropriate interval between doses. ${ }^{17}$ The Immunization program's ultimate aim is to reduce the incidence of VPDs by achieving high levels of coverage with potent vaccines administered at the appropriate ages and with the right intervals between multiple doses of vaccines. $^{18-21}$

Previous studies conducted in Ethiopia identified several factors related to incomplete childhood vaccination, such as the mother's age, parent's educational status, knowledge about vaccination, postnatal care utilization, mother's occupation, monthly income, and distance to health institutions. ${ }^{22-26}$ According to the Gindhir district's health office and zonal health department data, the district's vaccination coverage in 2018 and 2019 was $78 \%$ and $82 \%$, respectively. These vaccine coverage statistics put the district at high risk of outbreaks due to VPDs such as Measles (unpublished data; Gindhir District health office, Bale zone health department: health information management system annual report of childhood vaccination coverage, June 30, 2018 and 2019). Additionally, there is no current evidence regarding incomplete childhood vaccination determinants in southeast parts of Ethiopia. Therefore, this study was aimed to identify the determinants of incomplete childhood vaccination among children aged 12-23 months in Gindhir District, Southeast Ethiopia.

\section{Materials and Methods}

\section{Study Setting and Design}

A community-based unmatched case-control study design was employed with case to control the ratio of $1: 2$ in Gindhir District from 1-28 February 2020. Gindhir District is one of the Districts found in the Bale Zone composed of 5 urban and 32 rural kebeles. The total population in this District was 164,703, with 26,896 under-five children. According to the Gindhir District health office estimate, the number of children aged 12-23 months was 12,294 in 2019/20. The District has one general hospital, eight (8) health centers, and 32 health posts regarding health facilities' coverage.

\section{Source and Study Population}

The source and study population were all children between the ages of 12-23 months with their primary caretakers who had taken at least one dose of the routine vaccination program and residing in randomly selected kebeles (subdistrict) of the District. Cases were children 12-23 months who had missed at least one dose of the routine vaccination. Controls were children between the ages of 12-23 months who had completed the entire routine vaccination.

\section{Sample Size and Sampling Procedure}

The sample size was calculated using EPI INFO software version 7 for unmatched case-control study design. We considered maternal education as a significant determinant of incomplete childhood vaccination from previous studies, and we compared to get a large sample size. ${ }^{28,29} \mathrm{By}$ assuming a $10 \%$ non-response rate and applying $95 \%$ significance level with power at 80 , a total of 254 $(29.7 \%)$ from cases and $508(40.7 \%)$ among controls (1:2 ratio for the case: control), were obtained with a final sample size 762 (254 cases and 508 controls).

Initially, the kebeles in the District were stratified into urban and rural. Ten rural and three urban kebeles were selected randomly by lottery method from each stratum. All eligible cases and controls in selected kebeles were listed from the EPI registration books. Before actual data collection, a house-to-house survey of target children was done in each of the selected kebeles. During these visits, cases and controls were identified through interviews of mothers/primary caretakers and reviewing the vaccination card. After the survey, a sampling frame was prepared for each kebeles. For every case, controls were selected by a simple random sampling technique (lottery method) after proportionally 
allocating the number of children aged from 12 to 23 months to the number of children in each kebele.

\section{Data Collection Tool, Techniques, and Quality Assurance}

The data collection tool was adapted from previous studies $^{30-34}$ and was prepared in English, translated into the local language "Afan Oromo," and then translated back into English to ensure consistency. A pre-tested and structured data collection tool was used. Data were collected through face-to-face interviews of mothers/caretakers and by reviewing vaccination cards. Two supervisors and ten data collectors were recruited, and training was given on the data collection tool. Piloting the questionnaire was done before actual data collection to identify any potential problems and check the clarity by ensuring the tool accurately addressed the research questions. Piloting was done among 38 respondents, $5 \%$ of the total sample size in three kebeles which were not included in the study.

\section{Operational Definitions Case or Partially Vaccinated}

A child aged from 12 to 23 months old who missed at least one dose of the recommended routine vaccination consist of BCG, three doses of pentavalent, three doses of PCV, two doses of Rota vaccine, polio (three doses) and measles vaccines by the age of 12 months. ${ }^{35}$

\section{Control or Fully Vaccinated}

A child aged between 12 and 23 months old who received all recommended routine vaccination consist of $\mathrm{BCG}$, three doses of pentavalent, three doses of PCV, two doses of Rota vaccine, polio (three doses), and measles vaccines by the age of 12 months. ${ }^{35}$

\section{Primary Caretaker}

Mother or caretaker looking after the childbirth in the past two years of life and who was directly involved in vaccinating the child.

\section{Knowledge on Vaccination}

The knowledge questions were focused on vaccination and composed of eleven items. A score of 1 was given if the primary caretakers responded to the particular items correctly and 0 for incorrect. The sum of each item calculated and the mean value (7.34) was used as a cut-off point to categorize knowledge into two groups ( $>$ mean valuegood knowledge and $\leq$ Mean value- poor knowledge). ${ }^{32}$

\section{Data Processing and Analysis}

The collected data were checked manually for completeness, then coded and entered in Epi data version 3.1 and later exported to STATA Version 14. Descriptive statistics was done to present the data with the different variables by tables and graphs. The binary logistic regression model was used to identify the determinant variables. To control potential confounders, independent variables having P-value $<0.2$ in the bi-variable model were considered for multivariable logistic regression, and multicollinearity of independent variables was checked using variance inflation factor (VIF). Besides, model fitness was checked by Hosmer and Lemeshow goodness of test. Statistical significance of the determinants with incomplete childhood vaccination in the final model declared using 95\% confidence interval (CI) and p-value $<0.05$.

\section{Results}

\section{Socio-Demographic Characteristics}

A total of 254 cases and 508 controls were included in the study, with a response rate of 100\%. Around $679(89.1 \%)$ of primary caretakers were reported to have vaccination cards, and $83(10.9 \%)$ of them did not have vaccination cards. The majority of the children who participated in the study were from rural, $594(78 \%)$ and $438(57.5 \%)$ of the total children were males. Concerning the occupation of caretakers/mothers, about $35.2 \%$ cases and $64.8 \%$ of control caretakers were homemakers, respectively. About $33.7 \%$ of primary caretakers of cases and $66.3 \%$ of primary caretakers/mothers of controls were attended high school education (grade 9 to 12), respectively (Table 1).

\section{Reasons to Incomplete Childhood Vaccination and Types of Vaccines Defaulted}

The main reasons for incomplete childhood vaccination mentioned by primary caretakers/mothers of children were vaccine stock-out $(11.2 \%)$, and vaccine vial is not open for one or two children (7.3\%). Measles (16.1\%) and Penta 2 $(7.7 \%)$ were the most defaulted vaccines observed from selected children's vaccination cards (Figures 1 and 2).

\section{Determinants of Incomplete Vaccination}

Children born from mothers who had good knowledge of vaccination services were $50 \%$ times less likely to have incomplete vaccination than children whose mothers had poor knowledge $(\mathrm{AOR}=0.50,95 \% \mathrm{CI}$ : 0.30, 0.81). The children with primary caretakers who had no formal education were 
Table I Socio-Demographic Characteristics of Primary Caretakers/Mothers and Children Aged from 12 to 23 Months in Gindhir District, Southeast Ethiopia $(n=762)$

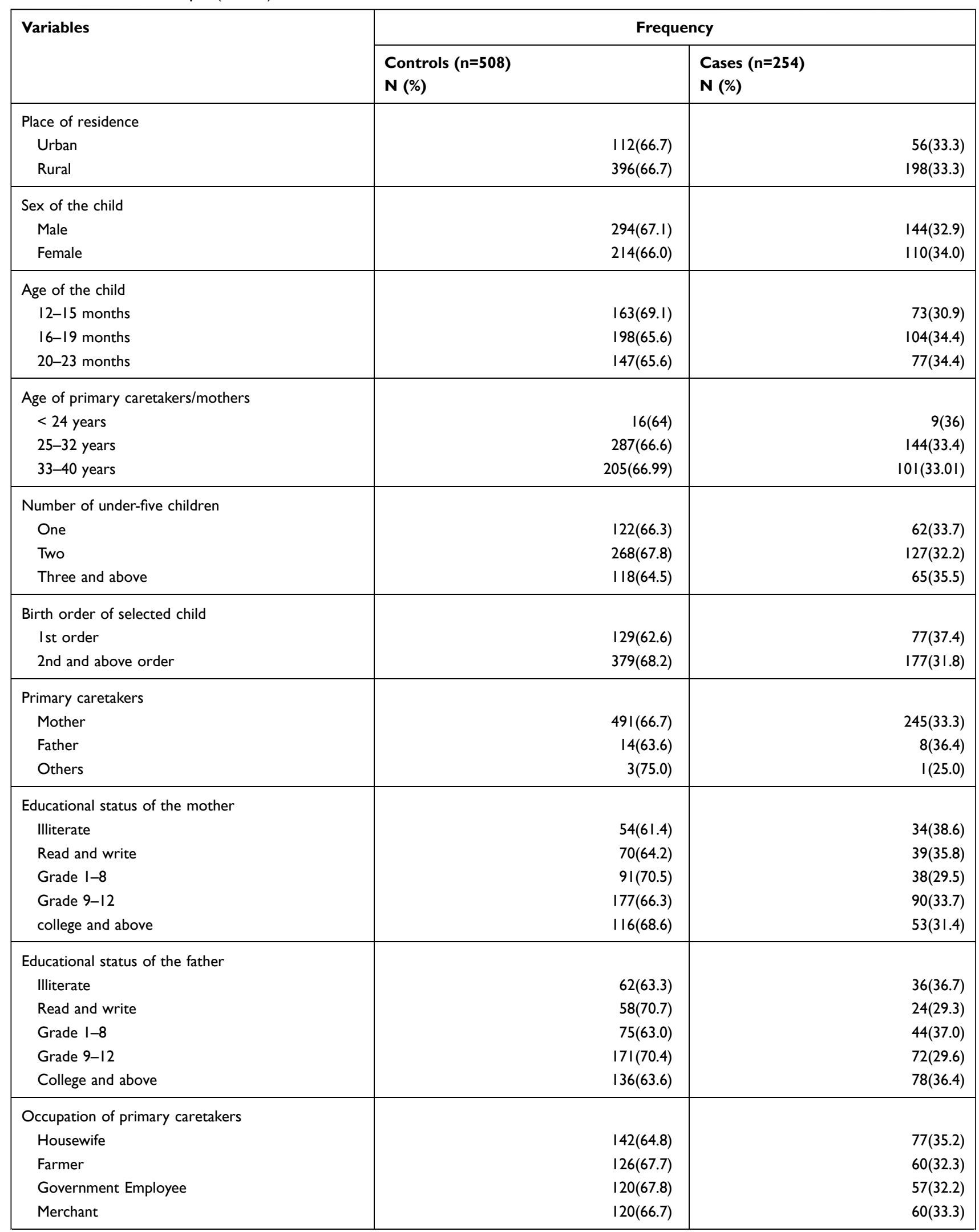


Table I (Continued).

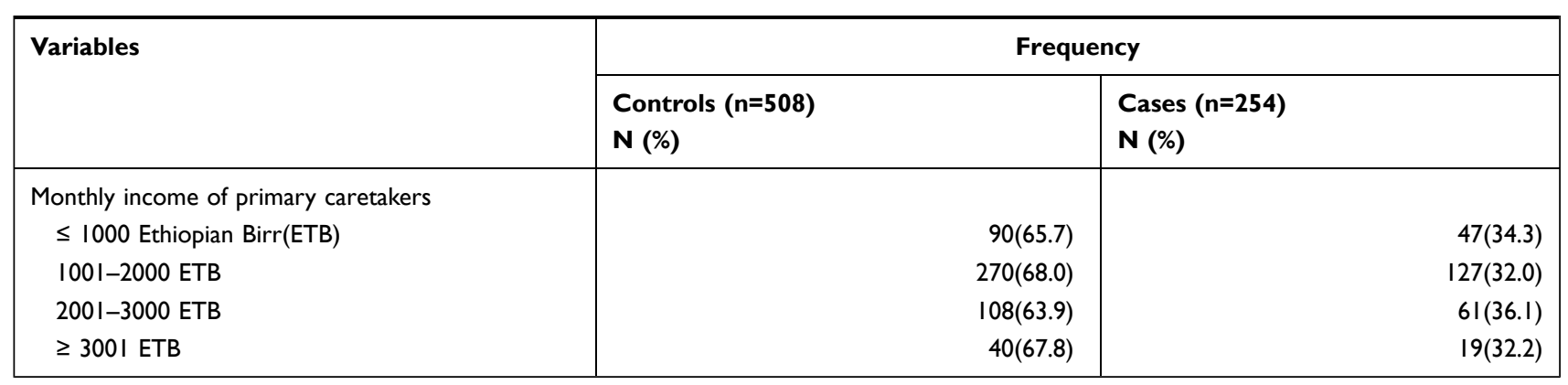

2.6 times more likely to default vaccination than those who attend college and above ( $\mathrm{AOR}=2.61,95 \% \mathrm{CI}: 1.19,5.67)$. The odds of having incomplete childhood vaccination was $55 \%$ less likely among children of primary caretakers who had been vaccinated in $3 \mathrm{rd}$ to 5 th doses of TT vaccine $(\mathrm{AOR}=0.45,95 \% \mathrm{CI}: 0.29,0.78)$. Similarly, the odds of having incomplete childhood vaccination was 2.50 times higher among mothers who not graduated as a model family $(\mathrm{AOR}=2.50,95 \% \mathrm{CI}: 1.51,4.14)$. The children on the second and above birth order were nearly six (6) times more likely to incomplete vaccination than those who were first birth order $(\mathrm{AOR}=6.34,95 \% \mathrm{CI}: 1.89,14.87)$. The odds of having incomplete vaccination among children of primary caretakers who had three and above under-five children were nearly five (5) times higher than their counterparts $(\mathrm{AOR}=4.90,95 \% \mathrm{CI}$ :
$1.72,13.93)$. The primary caretakers/mothers who had an average monthly income of above $3000 \mathrm{ETB}(\mathrm{AOR}=0.33$, $95 \% \mathrm{CI}: 0.15,0.77)$ were $67 \%$ less likely to default vaccination (Tables 2 and 3).

\section{Discussion}

Vaccination is one of the best influential and cost-effective health interventions to prevent vaccine-preventable diseases. It prevents devastating illness and disability and saves millions of lives every year. However, vaccination becomes more effective if the child can receive the full doses of vaccination. ${ }^{36,37}$ In this study, about one-third of children aged 12-23 months had not completed the recommended doses of vaccination. This finding was also consistent with the various studies from Indian states, which showed that $30 \%$ of the slum children

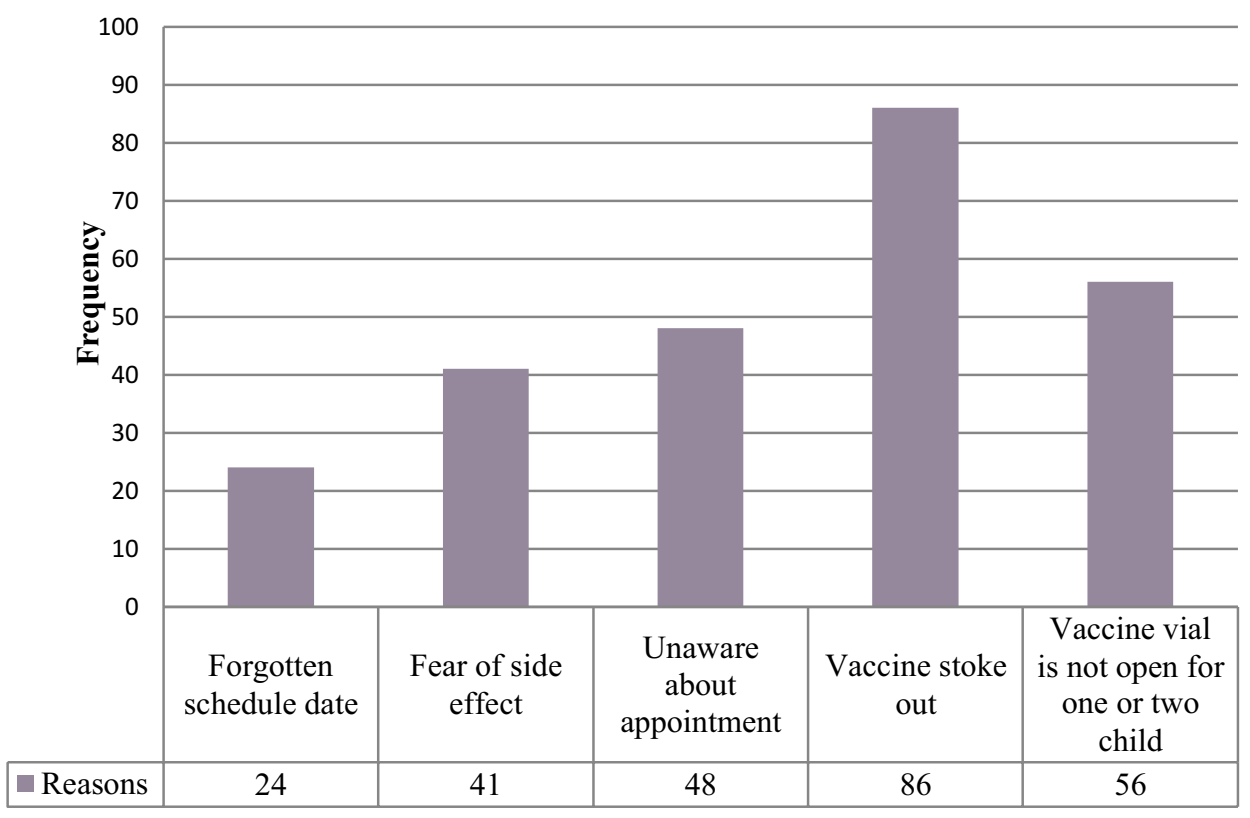

Figure I Shows the reasons for childhood incomplete vaccination mentioned by primary caretakers of children aged I2-23 months in Gindhir District, Southeast Ethiopia, 2020 . 


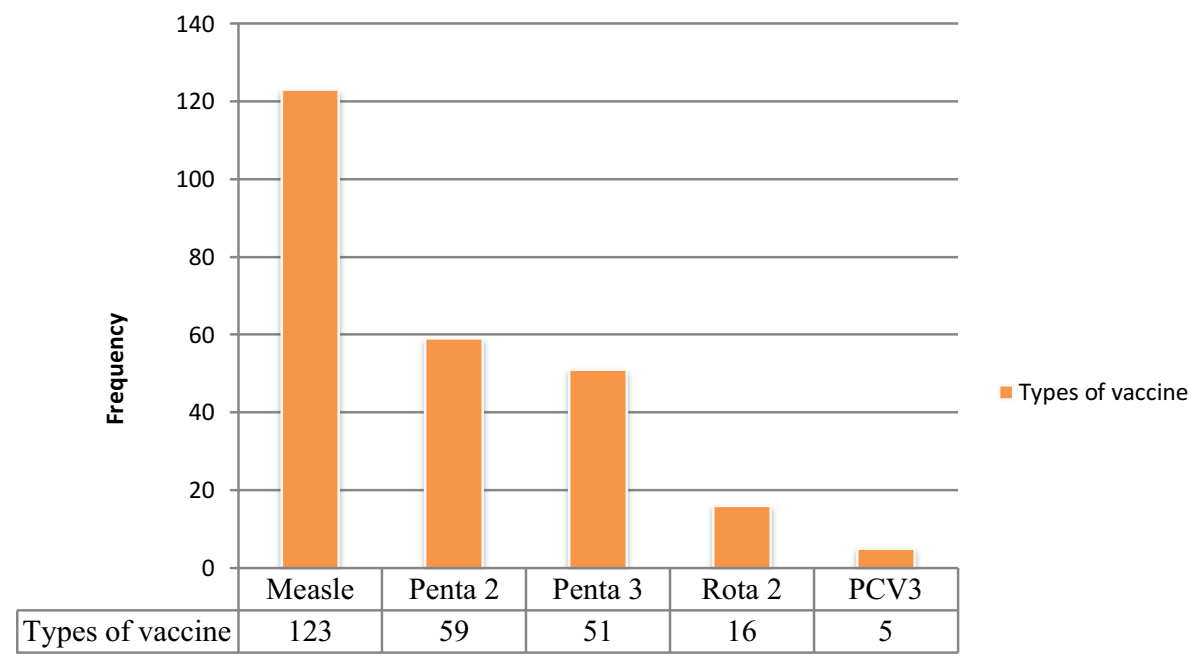

Figure 2 Shows types of vaccines defaulted by children aged 12-23 months in Gindhir District, Southeast Ethiopia, 2020.

have incomplete vaccination. ${ }^{38,39}$ Moreover, this finding is lower than the study finding in Sinana District, Ethiopia ${ }^{40}$ and higher than the study conducted in Nepal $(26 \%) .{ }^{41}$ This discrepancy might be due to different population characteristics and the duration of the study.

In this study, the most defaulted types of vaccines were measles and pentavalent vaccines, respectively. This result was consistent with other studies conducted in the urban slums of Lucknow district, Delhi in India ${ }^{42}$ and Nairobi, Kenya. ${ }^{43}$ This might be due to similar characteristics of the study population regarding defaulted vaccines. The major reasons mentioned in this study by primary caretakers/mothers of children were forgotten vaccination schedule, vaccine stoke out, fear of side effect, vaccine vials not open for one or two children. Of these reasons, vaccines stoke out and forgetting vaccination schedule were dominant reasons selected by primary caretakers/mothers. For this finding, there is no consistent and contradictory finding in Ethiopia and other countries. This might be due to different items used to assess reasons for incomplete childhood vaccination. The determinants of incomplete childhood vaccination identified in this study were 1) primary caretakers/mothers who vaccinated TT vaccine during their last pregnancy, 2) primary caretaker/ mother graduated as model family, 3) knowledge of primary caretakers/mothers on vaccination, 4) birth order, 5) the number of under-five children, 6) average monthly income and 7) educational status of primary caretakers/mothers. The children born from mothers who had good knowledge of vaccination service and its importance were $50 \%$ less likely to have incomplete vaccination status when compared to primary caretakers of children who had poor knowledge. This study finding was comparable with the previous studies done in Ethiopia ${ }^{40}$ and Kenya ${ }^{43}$, respectively. It is well recognized that the educational status of mothers plays an important role in health services utilization. Educational status may be a factor, which may have a positive influence on accepting the full vaccination of children. ${ }^{44,45}$ In this study, primary caretakers/mothers' educational status is the determinant of incomplete childhood vaccination. The children of primary caretakers/mothers who had no formal education were almost 2.6 times more likely to default vaccination than those who had a college education and above. This might be because educated mothers could have better knowledge and decisionmaking skills on different child health service issues, including the importance of vaccination of children compared to mothers who had no formal education. This finding is comparable with the study finding in Kenya and Bangladesh. ${ }^{43,45}$ The odds of having incomplete vaccination status among children of primary caretakers/mothers who vaccinated 3rd to 5th doses of TT vaccine were $55 \%$ less likely, and those who are not graduated as a model family were 2.5 times higher. This might be due to the mothers who take three to five doses of TT vaccine more aware of the importance of vaccination due to more health facility visits or healthcare provider contact. Similarly, the mothers who are not graduated as a model family might have no awareness of vaccination and related services delivered by health extension workers at the kebele (the lowest administrative) level. The children who had second birth order were nearly six (6) times more likely to default vaccination than first birth order and above birth order. This study finding was in line with the previous study conducted in Ethiopia. ${ }^{45}$ The primary caretakers/mothers who had average monthly income above 3000 ETB were $67 \%$ less likely to default vaccination. This finding is consistent with the study done in different parts of Ethiopia ${ }^{46,47}$ and Nouna district, Burkina Faso. 
Table 2 Bi-Variable Logistic Regression Analysis of Factors Associated with Incomplete Vaccination Among Children Aged 12-23 Months in Gindhir District, Southeast Ethiopia 2020 ( $\mathrm{n}=762$ )

\begin{tabular}{|c|c|c|c|c|}
\hline Variables & $\begin{array}{c}\text { Cases }(n=254) \\
n(\%)\end{array}$ & $\begin{array}{c}\text { Controls }(n=508) \\
n(\%)\end{array}$ & COR 95\% Cl & P-value \\
\hline \multicolumn{5}{|l|}{ Number of under-five children } \\
\hline One & $62(33.7)$ & $122(66.3)$ & 1 & \\
\hline Two & $127(32.2)$ & $268(67.8)$ & $4.15(1.43,9.69)^{*}$ & 0.001 \\
\hline Three and above & $65(35.5)$ & $118(64.5)$ & $5.4(1.55,13.87)^{*}$ & 0.001 \\
\hline \multicolumn{5}{|l|}{ Birth order of selected child } \\
\hline Ist order & $77(37.4)$ & $129(62.6)$ & I & \\
\hline 2nd order and above & $379(68.2)$ & $177(31.8)$ & $3.0(1.76,5.14)^{*}$ & $<0.001$ \\
\hline \multicolumn{5}{|c|}{ Monthly income of primary caretakers } \\
\hline$\leq 1000$ Ethiopian Birr(ETB) & $47(34.3)$ & $90(65.7)$ & I & \\
\hline $100 \mid-2000$ ETB & $127(32.0)$ & $270(68.0)$ & $0.75(0.38,1.50)$ & 0.421 \\
\hline $200 \mathrm{I}-3000$ ETB & $61(36.1)$ & $108(63.9)$ & $0.29(0.14,0.62)^{*}$ & 0.001 \\
\hline$\geq 3001$ ETB & $19(32.2)$ & $40(67.8)$ & $0.24(0.09,0.63)^{*}$ & 0.004 \\
\hline \multicolumn{5}{|l|}{ Educational status of the mother } \\
\hline Illiterate & $33(40.2)$ & $49(59.8)$ & $3.97(1.64,9.59)^{*}$ & 0.002 \\
\hline Read and write & $36(35.3)$ & $66(64.7)$ & $0.79(0.35,1.76)$ & 0.532 \\
\hline Grade I-8 & $36(29)$ & $88(7 I)$ & $1.05(0.49,2.23)$ & 0.324 \\
\hline Grade 9-12 & $99(33.8)$ & $174(66.2)$ & I.34(0.7I, 2.53) & 0.624 \\
\hline college and above & $5 I(30.9)$ & $114(69.1)$ & 1 & \\
\hline \multicolumn{5}{|l|}{ Educational status of the father } \\
\hline Illiterate & $36(36.7)$ & $62(63.3)$ & $2.13(0.93,4.92)$ & 0.075 \\
\hline Read and write & $24(29.3)$ & $58(70.7)$ & $2.45(1.15,4.64)^{*}$ & 0.035 \\
\hline Grade I-8 & $44(37.0)$ & $75(63.0)$ & $1.06(0.50,2.23)$ & 0.232 \\
\hline Grade 9-12 & $72(29.6)$ & $171(70.4)$ & $0.90(0.48,1.66)$ & 0.431 \\
\hline College and above & $78(36.4)$ & $136(63.6)$ & 1 & \\
\hline \multicolumn{5}{|l|}{ Graduated as a model family } \\
\hline Yes & $122(29.8)$ & $287(70.2)$ & $\mathrm{I}$ & \\
\hline No & $132(37.4)$ & $22 I(62.6)$ & $2.34(1.46,3.77)^{*}$ & $<0.001$ \\
\hline \multicolumn{5}{|l|}{ Number of TT vaccine doses } \\
\hline Ist and 2 nd doses & $113(37.3)$ & $190(62.7)$ & 1 & \\
\hline $3 r d$ to 5 th doses & $114(30.3)$ & $262(69.7)$ & $0.49(0.28,0.79)^{*}$ & 0.005 \\
\hline \multicolumn{5}{|l|}{ ANC service } \\
\hline Yes & $236(33)$ & $479(67)$ & I & \\
\hline No & $9(42.9)$ & $12(58.1)$ & $1.97(0.72,5.41)$ & 0.123 \\
\hline \multicolumn{5}{|l|}{ Birthplace of selected child } \\
\hline Home & $48(37.5)$ & $79(62.2)$ & 1 & \\
\hline Health center & $151(33.4)$ & $30 I(66.6)$ & $0.96(0.50,1.84)$ & 0.364 \\
\hline Hospital & $46(29.3)$ & III(70.7) & $0.22(0.27,1.03)$ & 0.059 \\
\hline \multicolumn{5}{|c|}{$\begin{array}{l}\text { Knowledge of primary caretakers/ } \\
\text { mothers }\end{array}$} \\
\hline Poor & $150(35.0)$ & $279(65.0)$ & 1 & \\
\hline Good & $104(31.2)$ & $229(68.8)$ & $0.50(0.32,0.85)^{*}$ & 0.004 \\
\hline
\end{tabular}

Note: $*(p<0.05$, Crude Odds ratio).

Abbreviations: ETB, Ethiopian Birr; ANC, antenatal care; TT, tetanus toxoid. 
Table 3 Multivariable Logistic Regression Analysis of Factors Associated with Incomplete Vaccination Among Children Aged 12-23 Months in Gindhir District, Southeast Ethiopia 2020 ( $n=762$ )

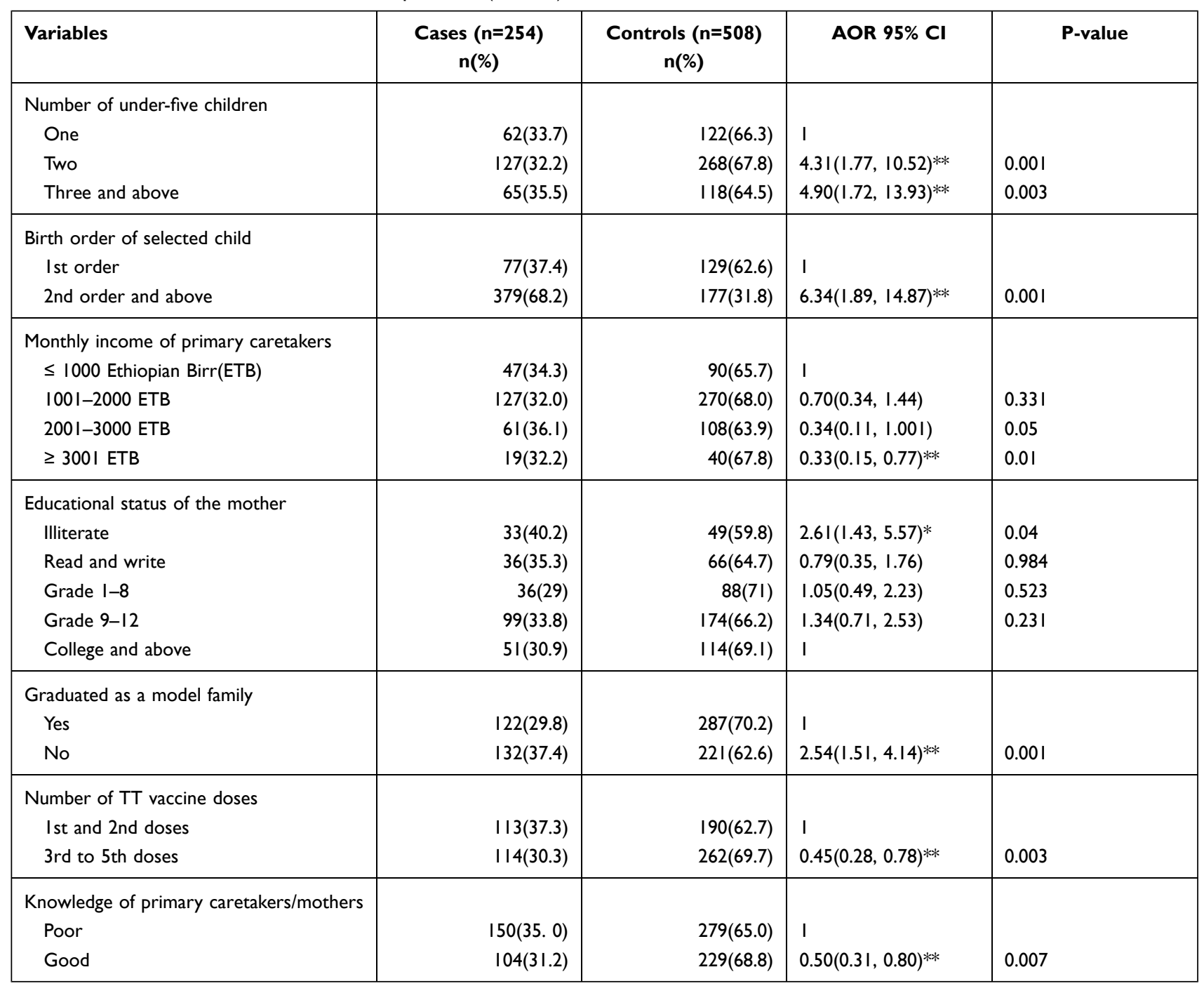

Notes: *Indicates the statistically significant association between dependant and independent variables in bivariable logistic regression analysis ( $\mathrm{p}<0.05)$, even though we consider the independent variable with $\mathrm{p}<0.2$ as a candidate for multivariable binary logistic regression. $* *$ ( $<<0.05$, Adjusted OR), I- reference category.

This might be due to the mothers of children who had stated average monthly income have the opportunity of affording hidden or indirect costs during vaccination service uptake like transportation.

\section{Limitation of the Study}

The study had several limitations that include cultural; the supply side and healthcare system-related factors were not deliberated or assessed. Moreover, some of the children (nearly one-tenth) had no vaccination cards. Therefore, the information about vaccination status had to be limited to the mother's verbal responses that might be liable to recall bias.

\section{Conclusion}

In this study, some socio-demographic factors like mother's educational status, average monthly income, graduated as model family, a number of under-five children, birth order of the selected child, knowledge on vaccination, and mothers provided TT vaccine, were identified as determinants of childhood incomplete vaccination. Improving maternal knowledge on vaccination service utilization, educational status, and income should be an expectable measure to reduce incomplete vaccination. 


\section{Abbreviations}

ANC, Antenatal Care; EPI, Expanded Program of Immunization; TT, Tetanus Toxoid; VPD, VaccinePreventable Diseases.

\section{Data Sharing Statement}

The datasets used and analyzed during the current study are available from the corresponding author on reasonable request.

\section{Ethical Consideration}

This study was conducted following the principles of Helsinki declarations. Following the study protocol, ethical clearance and approval were obtained from the Ethical Review Committee of Madda Walabu University Goba Referral Hospital and a formal letter from the research publication directorate and selected District. An information page was prepared in the local language and read to all included primary caretakers of selected children to obtain written informed consent. All study participants were informed about the purpose, risks of the study, and confidentiality of the information. Their involvement was voluntary, and notified that they had the right to refuse or stop at any data collection phase. The collected data were kept in a secure way to prevent unauthorized access. The primary caretakers whose children with incomplete vaccination status were counseled to complete all recommended vaccines for their next planned child.

\section{Acknowledgment}

We would like to thank all data collectors, supervisors, study participants, and Madda Walabu University for their helpful participation in this study.

\section{Author Contributions}

All authors made substantial contributions to conception and design, acquisition of data, or analysis and interpretation of data; took part in drafting the article or revising it critically for important intellectual content; agreed to submit to the current journal; gave final approval of the version to be published; and agree to be accountable for all aspects of the work.

\section{Funding}

The study was funded by Madda Walabu University.

\section{Disclosure}

The authors reported no conflicts of interest for this work.

\section{References}

1. Lee BY, Haidari LA. The importance of vaccine supply chains to everyone in the vaccine world Vaccine. Vaccine. 2017;35(35):4475. doi:10.1016/j.vaccine.2017.05.096

2. Vallbona C. Importance of immunization in child care and prevention. Child Adolesc Soc Work J. 1993;10(5):365-377. doi:10.1007/BF00844674

3. Danielsson N, Fakakovikaetau T, Szegedi E. Improved immunization practices reduce childhood hepatitis B infection in Tonga. Vaccine. 2009;27(33):4462-4467. doi:10.1016/j.vaccine.2009.05.051.

4. Lee EH, Lewis RF, Makumbi I, et al. Haemophilus influenzae type b conjugate vaccine is highly effective in the Ugandan routine immunization program: a case-control study. Trop Med Int Health. 2008;13 (4):495-502. doi:10.1111/j.1365-3156.2008.02027

5. Feikin DR, Flannery B, Hamel MJ, Stack M, Hansen PM. Vaccines for Children in Low-And Middle-Income Countries. world bank group economic review library; 2016. doi:10.1596/978-1-4648-0348-2

6. Campbell S. Increasing immunization coverage in developing countries. Primary Health Care. 2006;16(1):25. doi:10.7748/ phc2006.02.16.1.25.c592

7. Jani JV, De Schacht C, Jani IV, Bjune G. Risk factors for incomplete vaccination and missed opportunity for immunization in rural Mozambique. BMC Public Health. 2008;8(1):1-7. doi:10.1186/ 1471-2458-8-161

8. Babalola S. Determinants of the Uptake of the Full Dose of Diphtheria-Pertussis-Tetanus Vaccines (DPT3) in Northern Nigeria: a Multilevel Analysis. Matern Child Health J. 2009;13(4):550-558. doi:10.1007/s10995-008-0386-5

9. Lane S, MacDonald NE, Marti M, Dumolard L. Vaccine hesitancy around the globe: analysis of three years of WHO/UNICEF Joint Reporting Form data-2015-2017. Vaccine. 2018;36(26):3861-3867. doi:10.1016/j.vaccine.2018.03.063.

10. Rainey JJ, Watkins M, Ryman TK, Sandhu P, Bo A, Banerjee K. Reasons related to non-vaccination and under-vaccination of children in low and middle-income countries: findings from a systematic review of the published literature, 1999-2009. Vaccine. 2011;29 (46):8215-8221. doi:10.1016/j.vaccine.2011.08.096.

11. Simons E, Ferrari M, Fricks J, et al. Assessment of the 2010 global measles mortality reduction goal: results from a model of surveillance data. Lancet. 2012;379(9832):2173-2178. doi:10.1016/S01406736(12)60522-4.

12. UNICEF. Immunization Summary, a Statistical Reference Containing Data Through 2009. New York, USA: World Health Organization; 2011.

13. Alene M, Yismaw L, Berelie Y, Kassie B. Health care utilization for common childhood illnesses in rural parts of Ethiopia: evidence from the 2016 Ethiopian demographic and health survey. BMC Public Health. 2019;19(1):1-2. doi:10.1186/s12889-019-6397-x

14. VanderEnde K, Gacic-Dobo M, Diallo MS, Conklin LM, Wallace AS. Global routine vaccination coverage-2017. Morbidity Mortality Weekly Rep. 2018;67(45):1261. doi:10.15585/mmwr. mm6745a2

15. Federal Ministry of Health. Vaccination in Practice National Guideline for Health. Workers Ethiopia Health and Nutrition research institute; 2012.

16. Obahiagbon K, Odigie B. A Mobile Architecture For Childhood Vaccine-Preventable Illnesses Expert System. African J Computing ICT. 2015;8(2):Pp 61-74.

17. Tilahun B, Mekonnen Z, Sharkey A, et al. What we know and don't know about the immunization program of Ethiopia: a scoping review of the literature. BMC Public Health. 2020;20(1):1-4. doi:10.1186/ s12889-020-09304-1

18. Jonathan GE, Stoltenberg J. A tipping point for change: saving millions of additional lives in 2013 and beyond. Lancet. 2013;381 (9864):350-352. doi:10.1016/S0140-6736(13)60111-7. 
19. Reduce J, Mann C, Singh NS, et al. How Ethiopia achieved millennium development goal 4 through multisectoral interventions: a countdown to 2015 case study. Lancet Global Health. 2017;5(11): e1142-51. doi:10.1016/S2214-109X(17)30331-5

20. LaFond A, Kanagat N, Steinglass R, Fields R, Sequeira J, Mookherji S. Drivers of routine vaccination coverage improvement in Africa: findings from district-level case studies. Health Policy Plan. 2015;30(3):298-308. doi:10.1093/heapol/czu011.

21. Dessie DB, Negeri MA. Determining factors of full vaccination of children among 12-23 months old in rural Ethiopia. Am J Public Health. 2018;6(3):160-165.

22. Asmamaw A, Getachew T, Gelibo T, et al. Determinants of full valid vaccine dose administration among 12-32 months children in Ethiopia: evidence from the Ethiopian 2012 national vaccination coverage survey. Ethiopian J Health Dev. 2016;30(3):135-141.

23. Kassahun MB, Biks GA, Teferra AS. Level of vaccination coverage and associated factors among children aged 12-23 months in Lay Armachiho District, North Gondar Zone, Northwest Ethiopia: a community based cross-sectional study. BMC Res Notes. 2015;8 (1):1. doi:10.1186/s13104-015-1192-y

24. Meleko A, Geremew M, Birhanu F. Assessment of child vaccination coverage and associated factors with full vaccination among children aged 12-23 months at Mizan Aman town, Bench Maji Zone, Southwest Ethiopia. Int J Pediatr. 2017;24:2017. doi:10.1155/2017/7976587

25. Gebretsadik S, Gabreyohannes E. Determinants of under-five mortality in high mortality regions of Ethiopia: an analysis of the 2011 Ethiopia Demographic and Health Survey data. Int J Popul Res. 2016;2016:1-7. doi:10.1155/2016/1602761

26. Lakew Y, Bekele A, Biadgilign S. Factors influencing full immunization coverage among 12-23 months of age children in Ethiopia: evidence from the national demographic and health survey in 2011. BMC Public Health. 2015;15(1):1-8. doi:10.1186/s12889-015-2078-6

27. Aregawi HG, Gebrehiwot TG, Abebe YG, Meles KG, Wuneh AD. Determinants of defaulting from completion of child vaccination in Laelay Adiabo District, Tigray Region, Northern Ethiopia: a case-control study. PLoS One. 2017;12(9):e0185533. doi:10.1371/ journal.pone. 0185533

28. Asfaw AG, Koye DN, Demssie AF, Zeleke EG, Gelaw YA. Determinants of default to full completion of vaccination among children aged 12 to 23 months in south Ethiopia: an unmatched case-control study. Pan African Med J. 2016;23:1. doi:10.11604/ pamj.2016.23.100.7879

29. Porth JM, Wagner AL, Teklie H, Abeje Y, Moges B, Boulton ML. Vaccine non-receipt and refusal in Ethiopia: the expanded program on vaccination coverage survey, 2012. Vaccine. 2019;37 (15):2106-2121. doi:10.1016/j.vaccine.2019.02.045.

30. Mohammed H, Atomsa A. Assessment of child vaccination coverage and associated factors in Oromia regional state, eastern Ethiopia. Sci Tech Arts Res J. 2013;2(1):36-41. doi:10.4314/star.v2i1.98842

31. Etana B, Deressa W. Factors associated with complete immunization coverage in children aged 12-23 months in Ambo Woreda, Central Ethiopia. BMC Public Health. 2012;12(1):1-9. doi:10.1186/14712458-12-566

32. Yenit MK, Assegid S, Abrha H. Factors Associated With Incomplete Childhood Vaccination among Children 12-23 Months of Age in Machakel District, East Gojjam Zone. J Pregnancy Child Health. 2015;2(4):180. doi:10.4172/2376-127X.1000180
33. Habtamu B, Teklay K, Filimona B, Mitike M, Mounier-Jack S, Yayehyirad K. Routine immunization in Ethiopia. Ethiopian $J$ Health Dev. 2015;29(Special Issue 1):2-7.

34. Negussie A, Kassahun W, Assegid S, Hagan AK. Factors associated with incomplete childhood immunization in Arbegona district, southern Ethiopia: a case-control study. BMC Public Health. 2015;16 (1):1-9. doi:10.1186/s12889-015-2678-1

35. Vakili R, Hashemi AG, Khademi G, Abbasi MA, Saeidi M. Vaccination Coverage in WHO Regions: a Review Article. Int J Pediatr. 2015;3 (2-1):111-118.

36. World Health Organization. Measles vaccines: WHO position paper, April 2017-Recommendations. Vaccine. 2019;37(2):219-222. doi:10.1016/j.vaccine.2017.07.066

37. Chhabra P, Nair P, Gupta A, Sandhir M, Kannan AT. Vaccination in urbanized villages of Delhi. Indian J Pediatrics. 2007;74(2):131-134. doi:10.1007/s12098-007-0004-3

38. Kadri AM, Singh A, Jain S, Mahajan RG, Trivedi A. Study on vaccination coverage in urban slums of Ahmedabad city. Health Population. 2010;33(1):50-54.

39. Legesse E, Dechasa W. An assessment of child immunization coverage and its determinants in Sinana District, Southeast Ethiopia. $B M C$ Pediatr. 2015;15(1):1-4. doi:10.1186/s12887-015-0345-4

40. Shrestha S, Shrestha M, Wagle RR, Bhandari G. Predictors of incompletion of immunization among children residing in the slums of Kathmandu valley, Nepal: a case-control study. BMC Public Health. 2016;16(1):1-9. doi:10.1186/s12889-016-3651-3

41. Nat B, Singh JV, Awasthi S, Bhushan V, Kumar V, Singh SK. A study on determinants of immunization coverage among 12-23 months old children in urban slums of Lucknow district, India. Indian J Med Sci. 2007;61(11):598-606. doi:10.4103/0019-5359.37046

42. Mutua MK, Kimani-Murage E, Ettarh RR. Childhood vaccination in informal urban settlements in Nairobi, Kenya: who gets vaccinated. BMC Public Health. 2011;11(1):1. doi:10.1186/1471-2458-11-6

43. Angadi MM, Jose AP, Udgiri R, Masali KA, Sorganvi V. A study of knowledge, attitude and practices on vaccination of children in urban slums of Bijapur city, Karnataka, India. J Clin Diagnostic Res. 2013;7(12):2803. doi:10.7860/JCDR/2013/6565.3763

44. Rahman M, Obaida-Nasrin S. Factors affecting acceptance of complete vaccination coverage of children under five years in rural Bangladesh. Salud pública de méxico. 2010;52:134-140. doi:10.1590/S003636342010000200005

45. Tadesse H, Deribew A, Woldie M. Predictors of defaulting from completion of child immunization in south Ethiopia, May 2008-A case-control study. BMC Public Health. 2009;9(1):1-6. doi:10.1186/ 1471-2458-9-150

46. Okwaraji YB, Mulholland K, Schellenberg J, Andarge G, Admassu M, Edmond KM. The association between travel time to health facilities and childhood vaccine coverage in rural Ethiopia. A community-based cross-sectional study. BMC Public Health. 2012;12 (1):1-9. doi:10.1186/1471-2458-12-476

47. Sanou A, Simboro S, Kouyaté B, Dugas M, Graham J, Bibeau G. Assessment of factors associated with complete immunization coverage in children aged 12-23 months: a cross-sectional study in Nouna district, Burkina Faso. BMC Int Health Hum Rights. 2009;9(1):1-5. doi:10.1186/1472-698X-9-S1-S10. 


\section{Publish your work in this journal}

Risk Management and Healthcare Policy is an international, peerreviewed, open access journal focusing on all aspects of public health, policy, and preventative measures to promote good health and improve morbidity and mortality in the population. The journal welcomes submitted papers covering original research, basic science, clinical \& epidemiological studies, reviews and evaluations, guidelines, expert opinion and commentary, case reports and extended reports. The manuscript management system is completely online and includes a very quick and fair peer-review system, which is all easy to use. Visit http://www.dovepress.com/testimonials.php to read real quotes from published authors. 